\title{
ĐÁNH GIÁ BIẾN ĐỘNG ĐẤT NGẬP NƯỚC PHỤC VỤ XÂY DỬNG CÁC GIẢI PHÁP ĐA LỢI ÍCH SỦ DỤNG BỀN VỬNG TÀI NGƯŶ̂N ĐẤT NGẬP NƯ⿱̛́C TH! XÃ QUẢNG YÊN, TỈNH QUẢNG NINH VỚI SỰ HỖ TRỢ CỦA VIẼ̃N THÁM VÀ GIS
}

\author{
PGS. TS. NHỮ THI XUÂN \\ TS. ĐINH THI BẢO HOA \\ Trường Đại học Khoa học Tự nhiên, Đại học Quốc gia Hà Nội
}

\section{Tóm tắt:}

Bài báo tổng hợp, phân tích các yếu tố thành tạo và ảnh hưởng tới đất ngập nước thị xã Quảng Yên. Sử dụng phương pháp viễn thám và hệ thông tin địa lý thành lập ma trận biến động và các bản đồ hiện trạng, biến động lớp phủ mặt đất giai đoạn 2004 -2013, bản đồ hiện trạng đất ngập nước năm 2013 làm cơ sở đề xuất các giải pháp đa lợi ích sử dụng hợp lý đất ngập nước cho khu vực nghiên cứu. Phân tích các nguyên nhân gây biến động và đề xuất giải pháp đa lợi ích sử dụng hợp lý đất ngập nước khu vực nghiên cứu.

\section{1. Đặt vấn đề}

Đất ngập nước (ĐNN) có vai trò quan trọng đối với hệ sinh thái, con người, có giá trị lớn về kinh tế, văn hóa và đa dạng sinh học, song cũng là khu vực có tính nhạy cảm và dễ bị tổn thương, biến đổi bởi các tác nhân tự nhiên và con người.

Thị xã Quảng Yên là khu vực ven biển có diện tích lớn ĐNN. Tuy nhiên, trong những năm qua việc sử dụng tài nguyên đất nói chung, ĐNN nói riêng chưa hợp lý, thiếu căn cứ khoa học vững chắc và chưa được hoạch định một cách rõ ràng, gây ảnh hưởng lớn đến đời sống kinh tế, đồng thời có nguy cơ làm suy thoái tài nguyên và ô nhiễm môi trường đất. Vì vậy, việc đánh giá biến động ĐNN, xác định nguyên nhân gây ra biến động, nhằm xác lập cơ sở khoa học cho việc xây dựng các giải pháp đa lợi ích sử dụng bền vững tài nguyên đất ngập nước cho khu vực nghiên cứu là rất cần thiết.

Viễn thám và GIS là công cụ hiện đại trong đánh giá biến động ĐNN hiệu quả, khách quan. Trước thực trạng đó, nghiên cứu này tập trung phân tích, đánh giá các nhân tố thành tạo và ảnh hưởng tới ĐNN, ứng dụng viễn thám và GIS đánh giá biến động lớp phủ mặt đất (bởi vì lớp phủ mặt đất bao gồm các loại hình sử dụng đất, trong đó có ĐNN, khi ĐNN biến động cũng sẽ liên quan tới biến động các loại hình sử dụng đất khác), phân tích các nguyên nhân gây biến đổi ĐNN, trên cơ sở đó đề xuất các giải pháp đa lợi ích sử dụng bền vững tài nguyên đất ngập nước, góp phần tích cực cho công tác quy hoạch sử dụng đất khu vực nghiên cứu.

\section{Cách tiếp cận và phương pháp nghiên cứu}

Các yếu tố địa lý có mối quan hệ và tương tác chặt chẽ với nhau, nên đối tượng nghiên cứu ĐNN được đặt trong một hệ thống tổng thể và có tính đến lịch sử hình thành phát triển, nhằm đưa ra định hướng sử dụng ĐNN hợp lý, bền vững. Bài báo đã tiếp cận hệ thống, tổng hợp, lịch sử, phát triển bền vững, xã hội học để nghiên cứu ĐNN. Các phương pháp nghiên cứu: thu thập và phân tích tài liệu, điều tra khảo sát thực địa, đánh giá nhanh nông thôn, bản đồ, 
viễn thám, GIS và chuyên gia.

\section{Kết quả nghiên cứu và thảo luận}

\section{1. Đặc điểm các yếu tố hình thành đất ngập nước khu vực nghiên cứu}

Vị trí địa lý: Quảng Yên (trước đây là huyện Yên Hưng) là thị xã nằm ven biển ở phía Tây Nam của tỉnh Quảng Ninh, có lịch sử phát triển lâu đời, nằm trong trục kinh tế động lực ven biển quan trọng của vùng kinh tế trọng điểm Bắc Bộ, với diện tích tự nhiên là $31.420,20$ ha, chiếm $5,4 \%$ diện tích tự nhiên toàn tỉnh, có 19 đơn vị hành chính trực thuộc, trong đó có 11 phường.

Địa hình - địa mạo: Nằm trong vùng đồng bằng bồi tích cửa sông Bạch Đằng. Địa hình chủ yếu là đồng bằng ven biển có xen lẫn đồi núi thấp của dãy núi cánh cung Đông Triều chạy ra biển. Địa hình đa dạng, phức tạp và được chia thành 2 vùng rõ rệt: Vùng Hà Bắc: địa hình bị chia cắt mạnh, chủ yếu là đồi núi thấp, ruộng bậc thang, xen kẽ là những khu đất dốc, thấp dần về phía ven biển, có một số đồi cao, núi thấp. Xã Sông Khoai và các phường Tân $A n$, Hà An là vùng đất mới do khai hoang lấn biển, nên địa hình bằng phẳng hơn. Xã đảo Hoàng Tân địa hình chủ yếu là đồi núi, phần còn lại là địa hình thấp chịu ảnh hưởng của biển và các cửa sông bao quanh như sông Hốt, sông Bình Hương và sông Bến Giang. Vùng Hà Nam: nằm ở hữu ngạn sông Chanh, là vùng bãi bồi tạo nên do quai đê lấn biển, mở rộng các bãi bồi ven sông và bãi sú vẹt ven biển. Địa hình thấp trũng hình lòng chảo, chịu ảnh hưởng trực tiếp của biển nên đất chua mặn là chủ yếu. Khu ngoài đê là vùng bãi triều đã và đang được khoanh bao để nuôi trồng hải sản tạo điều kiện phát triển ngành thuỷ sản.

Khí hậu: Nhiệt đới gió mùa, nóng ẩm và mưa nhiều vào mùa hè, lạnh và khô vào mùa đông.

Hải văn: Thuỷ triều mang tính chất nhật triều đều, mỗi ngày có một lần nước lên và một lần nước xuống, biên độ thuỷ triều từ 3 $-4 m$.

Thủy văn: Mạng lưới dòng chảy khá dày đặc, chảy theo hướng Tây Bắc - Đông Nam rồi đổ ra biển qua các cửa sông. Dòng chính - sông Bạch Đằng chảy ở phía Tây, ngăn cách Quảng Yên với Hải Phòng. Các chi lưu chảy vào thị xã là nhánh sông Chanh và sông Rút bao lấy đảo Hà Nam rồi đổ ra biển Cát Bà, Cát Hải, còn nhánh Bạch Đằng đổ ra cửa Nam Triệu.

Tài nguyên nước: Có hồ Yên Lập với dung tích thường xuyên là 127,5 triệu m³ ${ }^{3}$, có khả năng đáp ứng, thoả mãn nhu cầu cung cấp nước cho sản xuất và sinh hoạt của nhân dân trong thị xã. Quy mô của hồ lớn, nguồn cấp nước dồi dào.

Thổ nhưỡng và tài nguyên đất: Là đồng bằng cửa sông ven biển, gồm các nhóm đất chính sau: Đất đồi núi: phân bố ở khu vực phía Bắc thị xã. Đất đồng bằng: chủ yếu là đất phù sa cổ và đất phù sa cũ nằm trong đê không được bồi hàng năm, phân bố ở hầu hết các xã phường trong thị xã, nhưng tập trung ở khu vực Hà Nam. Đất bãi bồi cửa sông ven biển: gồm các loại đất mặn và đất cát, phân bố ở các khu vực ven biển và cửa sông,...

\subsection{Các yếu tố ảnh hưởng tới đất ngập nước khu vực nghiên cứu}

- Dân số và lao động: Năm 2004, dân số trung bình của Quảng Yên là 134.964 người, mật độ 422 người/ $/ \mathrm{km}^{2}$ và đến năm 2011, dân số đã tăng lên 139.596 người. Dân số tăng, nhu cầu đất cho xây dựng nhà ở tăng, dẫn đến việc chuyển đổi mục đích sử dụng đất từ các loại hình khác sang đất ở, trong đó có san lấp ĐNN làm nhà ở diễn ra ngày càng nhiều. Giai đoạn 2004-2013 đã chuyển 236,25 ha đất lúa sang đất ở và chuyên dùng (bảng 1).

- Quai đê lấn biển: Trong quá trình phát triển kinh tế - xã hội, Quảng Yên đã được 
cải tạo và mở rộng để trồng trọt và định cư. Quá trình quai đê, lấn biển, khai thác bãi bồi và các hoạt động phát triển đã tác động mạnh mẽ đến cảnh quan tự nhiên làm hình thành các kiểu thảm thực vật thứ sinh nhân tác nhạy cảm và các kiểu sử dụng đất trong mối phụ thuộc vào động lực sông - biển triều. Hoạt động quai đê lấn biển đã tạo ra các dạng bãi triều cao được khai hoang.

- Nuôi trồng thủy sản: Trong khoảng 20 năm trở lại đây, các đầm nuôi trồng thủy sản có sự phát triển gia tăng. Điển hình là khu vực Bình Hương và đầm Nhà Mạc. Mặc dù những phương thức khai thác ven biển hiện nay đã hình thành các hệ sinh thái nước lợ có năng suất sinh học và giá trị kinh tế cao hơn nhiều lần các hệ sinh thái nước ngọt, nhưng thường khai thác không bền vững. Xây dựng các đầm thuỷ sản làm tăng xâm nhập mặn; nước thải từ các đầm nuôi tôm làm ô nhiễm môi trường đất và nước, hệ quả làm giảm năng suất nuôi trồng; việc xây dựng các đầm nuôi còn làm tăng nguy cơ xói lở bờ biển, vỡ đê do chặt phá rừng ngập mặn.

- Chặt phá rừng ngập mặn: Diện tích rừng ngập mặn đang chịu sức ép rất lớn từ phát triến nuôi trồng thủy sản và khai thác lâm sản. Do chưa nhận thức đầy đủ về giá trị rừng ngập mặn nên người dân phá rừng để nuôi trồng và khai thác thủy sản ồ ạt. Diện tích rừng ngập mặn giảm, nguồn thức ăn thực vật và dinh dưỡng của các loài sinh vật sống ở sông, biển cũng giảm.

- Các hoạt động khác: Việc xây dựng đường giao thông, cầu cảng, khu đô thị và công nghiệp không những tàn phá nguồn tài nguyên đa dạng sinh học trong hệ sinh thái rừng ngập mặn, còn gây rất nhiều ảnh hưởng đến môi trường (chất thải sinh hoạt, công nghiệp, dầu thải) làm nhiều sinh vật chết hoặc bỏ đi nơi khác. Ngoài ra, còn gây xói lở bờ sông do hoạt động của tàu thuyền có công suất lớn.

\section{3. Đánh giá biến động đất ngập} nước khu vực nghiên cứu trên cơ sở ứng dụng viễn thám và GIS

Để đánh giá biến động ĐNN, nghiên cứu đã sử dụng 2 ảnh SPOT-5 chụp khu vực nghiên cứu năm 2004 và 2010. Bản đồ địa hình 1:50.000 năm 2001, thành lập bản đồ hiện trạng lớp phú mặt đất ở hai thời điểm:

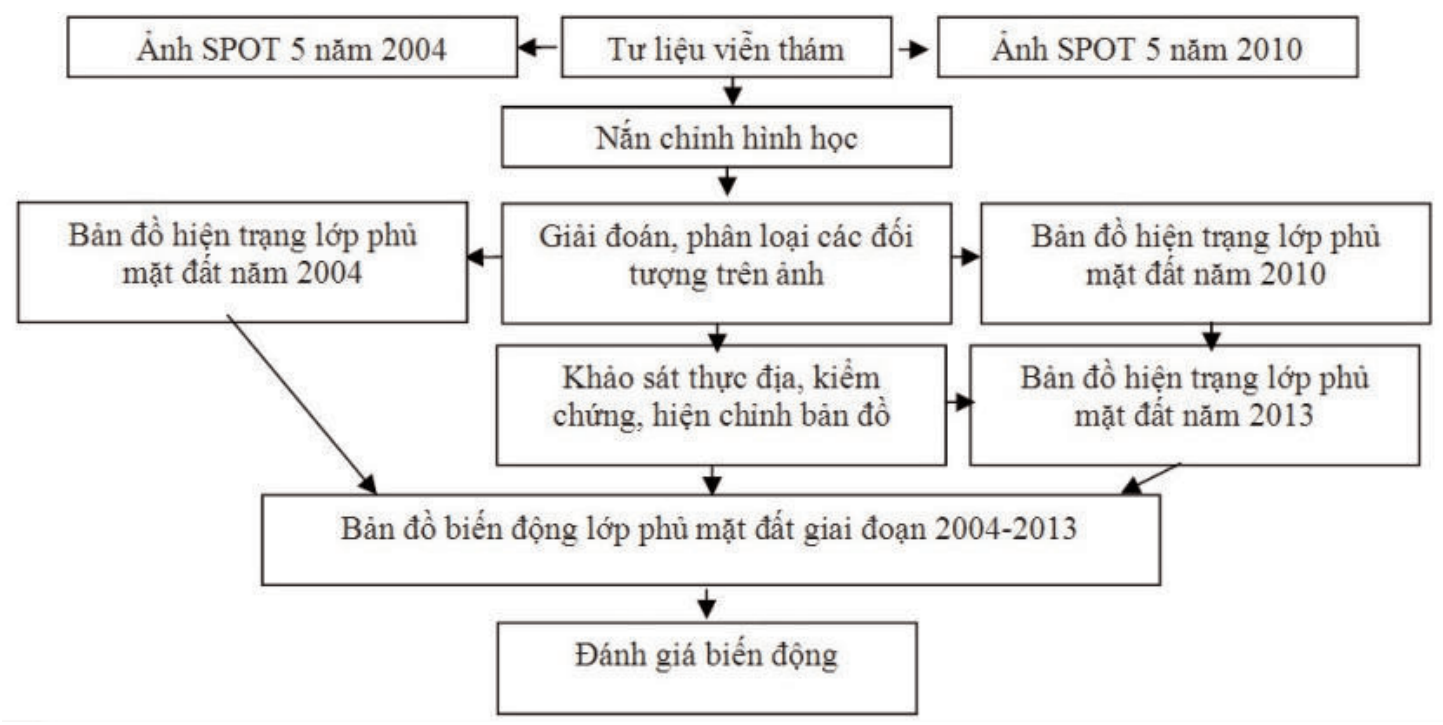

Hình 1: Sơ đồ quy trình đánh giá biến động lớp phủ mặt đất thị xã Quảng Yên giai đoạn 2004 - 2013 trên cơ sở ứng dụng viển thám và GIS 


\section{Trao đổi - Ý kiến}

BÁN ĐO HIẸN TRẠ

THI XĀ QUÁNG YÊN, TINHH QUÁNG NINH

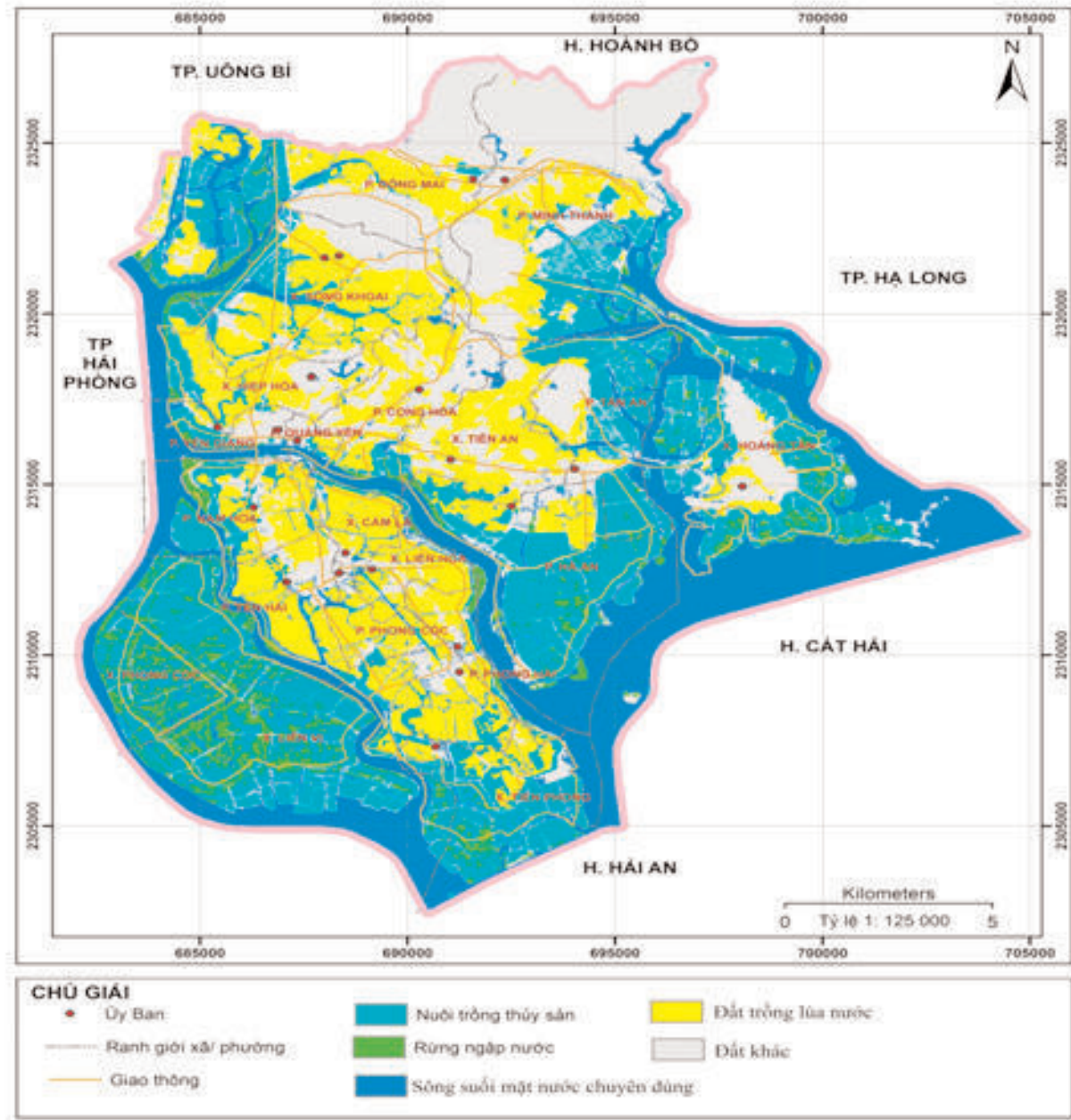

Hình 2: Hiện trạng đất ngập nước năm 2013 thị xã Quảng Yên

2004 và 2010, kết hợp điều tra thực địa hiện chỉnh thành lập bản đồ hiện trạng sử dụng đất năm 2013. Từ 2 bản đồ này xây dựng bản đồ biến động lớp phủ mặt đất giai đoạn 2004-2013 (hình 3) và ma trận biến động lớp phủ mặt đất giai đoạn 2004-2013 theo sơ đồ ở hình 1. Từ bản đồ hiện trạng sử dụng đất năm 2013, biên tập thành lập bản đồ hiện trạng ĐNN năm 2013 (hình 2). Nghiên cứu đã sử dụng các phần mềm GIS: IDRISI, Ecognition, ARCGIS, ArcMap để xử lý ảnh và thành lập bản đồ. (Xem hình 1, 2, 3, bảng 1).
Theo kết quả biến động (bản đồ và bảng ma trận biến động) cho thấy quá trình đô thị hóa diễn ra khá nhanh tập trung ở các khu vực chính là đô thị Quảng Yên, các xã Tiền An, Tân An và khu vực bán đảo Hà Nam. Các khu vực này có sự biến đổi về mục đích sử dụng đất từ trồng lúa và hoa màu sang diện tích đất ở; hoặc đổ đất, san lấp một phần diện tích ĐNN để hình thành các khu vực quần cư, sản xuất công nghiệp.

Khu vực ĐNN phát triển rừng ngập mặn chủ yếu chỉ còn tập trung ở khu vực bãi triều đầm Nhà Mạc, một diện tích nhỏ ở khu 
BẢN ĐO BIEN ĐQNG LÓP PHỦ MAT ĐAT GIAI ĐOẠN 2004-2013 THI XĀ QUANG YEN, TINH QUANG NINH

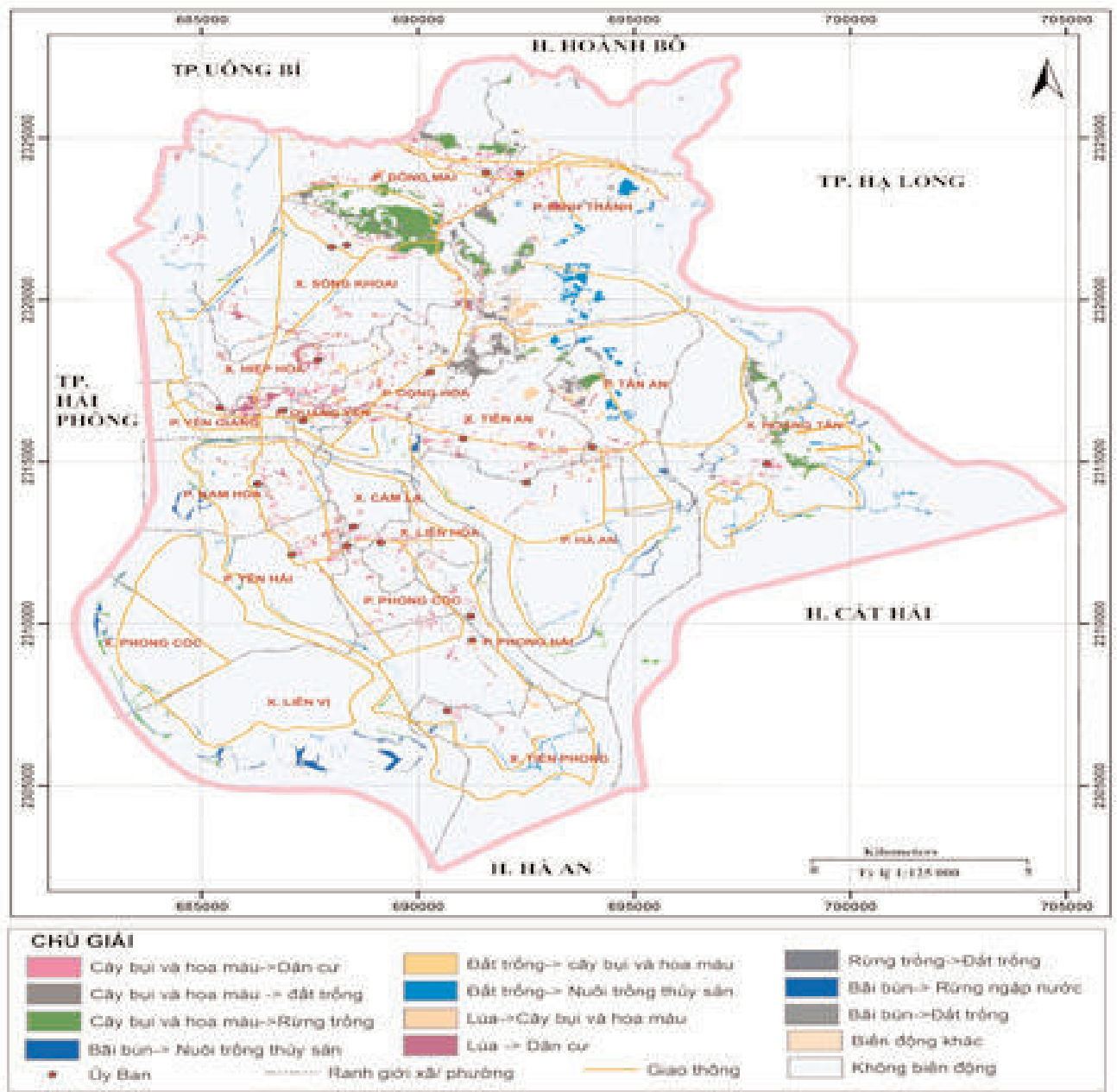

Hình 3: Bản đồ biến động lớp phủ mặt đất giai đoạn 2004 - 2013

Hoàng Tân và rải rác ở các khu vực bãi triều khác nhưng chủ yếu là các trảng cây bụi rậm thấp được sử dụng kết hợp để nuôi trồng thủy sản. Diện tích rừng ngập mặn trong khu vực có xu hướng giảm khá rõ rệt.

Diện tích nuôi trồng thủy sản được mở rộng đáng kể tại phía đông Quảng Yên và phía nam đầm Nhà Mạc, đầm Liên Hòa và bãi triều của các xã/phường Hà An, Tân An, Hoàng Tân và Minh Thành. Đây là một sự biến đổi theo chiều hướng tích cực nhằm làm giảm diện tích đất bỏ hoang. Hiện nay, diên tích các đầm nuôi vẫn tiếp tục được mở rộng mạnh mẽ và hình thành những khu vực nuôi trồng thủy sản mới.

\subsection{Phân tích nguyên nhân biến đổi đất ngập nước tại khu vực nghiên cứu}

Nguyên nhân gây biến đổi của khu vực trong giai đoạn này phụ thuộc nhiều vào các hoạt động phát triển kinh tế - xã hội:

- Bắc Yên Hưng: Sự biến đổi diễn ra khá mạnh mẽ. Có thể thấy 2 hướng biến đổi lớn nhất là sự biến đổi đất trống sang rừng 
Bảng 1: Ma trận biến động diện tích các loại hình lớp phủ mặt đất giai đoạn 2004 - 2013 khu vực nghiên cứu

\begin{tabular}{|c|c|c|c|c|c|c|c|c|c|}
\hline Năm 2004 & $\begin{array}{c}\text { Bãi } \\
\text { bùn }\end{array}$ & $\begin{array}{c}\text { Cây bụi } \\
\text { và hoa } \\
\text { màu }\end{array}$ & $\begin{array}{c}\text { Đất ờ } \\
\text { và } \\
\text { chuyên } \\
\text { dùng }\end{array}$ & $\begin{array}{c}\text { Đất } \\
\text { trống }\end{array}$ & Lúa & $\begin{array}{c}\text { Mặt } \\
\text { nước }\end{array}$ & $\begin{array}{c}\text { Nuôi } \\
\text { trồng } \\
\text { thủy sản }\end{array}$ & $\begin{array}{c}\text { Rừng } \\
\text { ngập } \\
\text { mặn }\end{array}$ & $\begin{array}{c}\text { Rừng } \\
\text { trồng }\end{array}$ \\
\hline Bãi bùn & 61,88 & 1,25 & 5,44 & 59,74 & 2,77 & 1,24 & 114,02 & 78,1 & \\
\hline $\begin{array}{c}\text { Cây bụi và hoa } \\
\text { màu }\end{array}$ & 2,4 & 1379,61 & 239,83 & 83,54 & 4,6 & 5,8 & 5,72 & 1,49 & 40,82 \\
\hline $\begin{array}{c}\text { Đất ở và } \\
\text { chuyên dùng }\end{array}$ & 0,98 & 23,71 & 2101,71 & 8,46 & 0 & 15,43 & 2,87 & 0 & 0 \\
\hline Đất trống & 6,2 & 66,06 & 5,69 & 814,57 & 0 & 0,54 & 257,45 & 1,3 & 5,4 \\
\hline Lúa & 1,69 & 317,78 & 236,250 & 7,2 & 6109,83 & 4,5 & 12,3 & 0 & 1,19 \\
\hline Mặt nước & 5,3 & 0 & 0,2 & 0,13 & 0 & 5984,64 & 0,19 & 0,4 & 0 \\
\hline $\begin{array}{c}\text { Nuôi trồng thủy } \\
\text { sản }\end{array}$ & 2,8 & 0,23 & 12,32 & 3,8 & 0 & 0,84 & 8298,47 & 3,4 & 0 \\
\hline $\begin{array}{c}\text { Rừng ngập } \\
\text { mặn }\end{array}$ & 1,99 & 0,78 & 0 & 3,67 & 0 & 1,87 & 0,67 & 1054,8 & 0 \\
\hline Rừng trồng & 0,16 & 6,32 & 10,84 & 46,38 & 0,27 & 0,35 & 0 & 0 & 1894,02 \\
\hline
\end{tabular}

trồng và cây lâu năm, và sự mở rộng của đất ở dọc quốc lộ 18 và quốc lộ 10. Diện tích đất trống cũng được biến đổi sang đất lúa và hoa màu. Nhìn chung, sự biến đổi vùng Bắc Yên Hưng là theo chiều hướng tích cực. Xu hướng tích cực này có được là do chủ trương chính sách khuyến khích phủ xanh đất trống đồi trọc, tăng cường diện tích rừng trồng trên khu vực đồi núi thấp. Sự phát triển của các khu đô thị và khu công nghiệp dọc đường quốc lộ thể hiện quá trình phát triển kinh tế - xã hội của khu vực.

- Khu vực đô thị Quảng Yên: vùng được phân ra làm hai loại rõ rệt là đất lúa và hoa màu, đất ở. Sự biến đổi của vùng theo xu hướng chính là chuyển dần đất lúa và hoa màu sang đất ở. Trong vùng này còn một diện tích rừng trồng và cây lâu năm trên khu vực đồi thấp. Tuy nhiên, toàn bộ diện tích này cũng đã chuyển sang đất ở. Xu hướng biến đổi đất nông nghiệp - đô thị Quảng Yên bị tác động mạnh mẽ bởi quá trình đô thị hóa nhằm mở rộng và nâng cấp đô thị Quảng Yên. Đây là nguyên nhân chính gây ra các biến đổi của khu vực.

- Khu vực Đông Quảng Yên: Đây là khu vực có sự biến đổi theo 3 xu hướng chính. Xu hướng mạnh mẽ nhất là sự suy giảm diện tích lớn rừng ngập mặn chuyển sang nuôi trồng thủy sản. Vào những năm 2004, chính sách cho vay vốn mở đầm nuôi tôm đã mở rộng một diện tích lớn các đầm nuôi và kéo theo diện tích rừng ngập mặn bị phá hủy. Hiện nay, diện tích các đầm nuôi vẫn tiếp tục được mở rộng mạnh mẽ và đã hình thành khu vực nuôi trồng thủy sản khá lớn ở Bình Hương. Bên cạnh đó, một diện tích lớn đất trống cũng đã được cải tạo thành các khu vực nuôi trồng thủy sản. Đây là một sự biến đổi theo chiều hướng tích cực nhằm 
làm giảm diện tích đất bỏ hoang. Một diện tích lớn đất trống trên khu vực đồi núi thấp phía tây khu vực cũng đã được biến đổi sang rừng trồng và cây lâu năm. Hiện nay, diện tích loại này có sự suy giảm nhưng không đáng kể do quá trình đô thị hóa.

- Khu vực Hà Nam: Hà Nam có 3 loại chính là đất lúa, hoa màu và đất ở. Sự biến đổi có xu hướng tương tự ở khu vực đô thị Quảng Yên. Đất lúa và hoa màu có xu hướng biến đổi sang đất ở. Tuy nhiên, sự phát triển của xu hướng này không mạnh mẽ như ở đô thị Quảng Yên.

- Khu vực Nam Quảng Yên: Xu hướng nuôi trồng thủy sản tăng diện tích đáng kể.

\section{5. Đề xuất các giải pháp đa lợi ích sử dụng bền vững tài nguyên đất ngập nước thị xã Quảng Yên}

Để phục vụ cho nhu cầu lương thực tại chỗ, khu vực đồng bằng trũng Sông Khoai cần duy trì diện tích trồng lúa và hoa màu ở đây, bởi khu vực này cũng rất thích hợp để phát triển nông nghiệp.

Nơi lý tưởng để phát triển nuôi trồng thủy sản thâm canh quy mô lớn đó là khu vực bãi triều phường Minh Thành và Tân An (phía Đông Quảng Yên), bên cạnh đó cần duy trì môi trường nuôi trồng đảm bảo để tăng năng suất và bảo vệ môi trường khu vực rừng ngập mặn xung quanh. Nơi đây đang có rất nhiều ưu thế để phát triển kinh tế và xã hội.

Tại khu vực đảo Hoàng Tân với dự án phát triển các khu du lịch sinh thái (liên kết với thành phố Hạ Long), diện tích rừng ngập mặn sẽ bị đe dọa bởi hoạt động du lịch. Chức năng sinh thái và chức năng kinh tế cần được duy trì là chức năng chính của ĐNN ở đây. Như vậy thì việc nuôi trồng thủy sản và phát triển du lịch có thể phát triển hài hòa mà không ảnh hưởng đến môi trường.

Hà Nam là nơi được hình thành do quá trình quai đê lấn biển từ lâu đời. Hiện nay, đây là khu vực chuyên canh lúa và hoa màu, cung cấp lương thực thực phẩm cho thị xã và các vùng lân cận. Nơi đây sẽ giữ chức năng sản xuất, cung cấp các dạng tài nguyên tái tạo từ phát triển nông nghiệp chuyên canh.

Khu vực đầm Nhà Mạc có diện tích rừng ngập mặn với quy mô lớn nhất trong vùng và đã bị suy giảm đáng kể. Định hướng quy hoạch phát triển kinh tế theo hướng phát triển kinh tế biển và các khu công nghiệp sẽ phá hủy toàn bộ diện tích rừng ngập mặn tại đây. Không chỉ rừng ngập mặn bị tiêu diệt mà hệ sinh thái giàu có trong khu vực sẽ bị phá hủy. Trong khi đó, nền địa chất và vị trí địa lý ở đây không thích hợp cho sự phát triển của các khu công nghiệp bởi đây là khu vực bãi triều thường xuyên chịu ảnh hưởng của thủy triều và các tai biến thiên nhiên như bão lũ. Xây dựng hệ thống rừng ngập mặn phòng hộ trong khu vực này kết hợp với nuôi trồng thủy sản là một hướng đi hợp lý hơn cả. Trong khi biến đổi khí hậu và mực nước biển dâng cao đang là mối đe dọa cho các khu vực ven biển thì chức năng sinh thái nhằm duy trì các dòng vật chất năng lượng nên được chú trọng là chức năng chính.

Nên hoạch định các vùng chuyên canh cây nông nghiệp và nuôi trồng thủy sản kết hợp với áp dụng tiến bộ khoa học kĩ thuật kết hợp nâng cao kết cấu hạ tầng cho sản xuất sẽ tạo sự đa dạng hóa sản phẩm có giá trị cao, tạo thành vùng sản xuất tập trung và vành đai thực phẩm, cung cấp cho chế biến, xuất khẩu.

\section{Kết luận}

Việc nghiên cứu đặc điểm và biến động ĐNN, phục vụ đề xuất các giải pháp đa lợi ích sử dụng hợp lý ĐNN thị xã Quảng Yên, tỉnh Quảng Ninh là cần thiết, góp phần quan trọng trong việc nâng cao chất lượng quản lý đất đai nói chung và ĐNN nói riêng, từ đó, đưa ra các giải pháp sử dụng và khai thác 
hợp lý ĐNN.

Để nghiên cứu biến động ĐNN, tư liệu viễn thám và công nghệ GIS đem lại hiệu quả cao. Tư liệu viễn thám đóng vai trò quan trọng trong khai thác thông tin lớp phủ mặt đất, trong đó có ĐNN ở những thời điểm thu nhận ảnh, nếu kết hợp điều tra khảo sát thực địa cho phép thành lập bản đồ ở thời điểm khảo sát thực địa một cách hiệu quả. Công nghệ GIS đóng vai trò quan trọng trong việc tích hợp thông tin và tính toán biến động cho việc theo dõi biến động lớp phủ mặt đất.

Qua đánh giá biến động lớp phủ mặt đất cho thấy nhiều diện tích đất trồng lúa và hoa màu chuyển sang đất ở, diễn ra tình trạng đổ đất, san lấp một phần diện tích ĐNN để hình thành các khu vực đất ở, sản xuất công nghiệp. Còn khu vực ĐNN nuôi trồng thủy sản chủ yếu phân bố trên các bãi triều khu vực đầm Nhà Mạc, đầm Liên Hòa và bãi triều của một số xã/phường. Sự mở rộng các đầm nuôi trồng thủy sản với quy mô lớn là nguyên nhân chính dẫn đến sự suy giảm rừng ngập mặn khu vực nghiên cứu.

Công trình được thực hiện dưới sự hỗ trợ của đề tài QG 12 20.0

\section{Tài liệu tham khảo}

[1]. Cục Bảo vệ Môi trường Việt Nam, IUCN (2005), Báo cáo Tổng quan hiện trạng đất ngập nước Việt Nam sau 15 năm thực hiện Công ước Ramsar, Hà Nội.

[2]. Mai Trọng Nhuận (2010). Dự án "Điều tra, đánh giá, thống kê, quy hoạch các khu bảo tồn vùng đất ngập nước có ý nghĩa quốc tế, quốc gia".

[3]. Nguyễn Cao Huần và nnk (2009), Quy hoạch bảo vệ môi trường tỉnh Quảng Ninh và các khu vực trọng điểm đến năm 2020. Khoa Địa lý, trường Đại học Khoa học Tự nhiên, Đại học Quốc gia Hà Nội.

[4]. UBND huyện Yên Hưng, Niên giám thống kê năm 2005 và năm 2010.0

\section{Summary}

Application of Remote Sensing and GIS for analysis of wetland for building multibenefit solution to sustainable uses of wetland in Quang Yen commune, Quang Ninh province

\section{Assoc. Prof. Dr. Nhu Thi Xuan}

Dr. Dinh Thi Bao Hoa

\section{University of Science, Vietnam National University, Hanoi}

This research focuses on analyzing factors that affect the formation and structure of wetland in Quang Yen commune. By using Remote sensing and GIS technology, we contructed land cover map and land cover change map during the period 2004 - 2013, wetland map 2013. The maps are used as bases for analyzing driving forces of changes and for the orientation of sustainable uses and management of wetlands in the study area as well as for suggestions and recommendations. $O$

Ngày nhận bài: 24/10/2014. 